REVIEW ARTICLE

\title{
Dendritic cell migration in inflammation and immunity
}

\author{
Juan Liu ${ }^{1 凶},{\text { Xiaomin } \text { Zhang }^{1}, \text { Yujie Cheng }}^{1}$ and Xuetao Cao ${ }^{1,2}$ \\ (c) The Author(s), under exclusive licence to CSI and USTC 2021
}

Dendritic cells (DCs) are the key link between innate immunity and adaptive immunity and play crucial roles in both the promotion of immune defense and the maintenance of immune tolerance. The trafficking of distinct DC subsets across lymphoid and nonlymphoid tissues is essential for DC-dependent activation and regulation of inflammation and immunity. DC chemotaxis and migration are triggered by interactions between chemokines and their receptors and regulated by multiple intracellular mechanisms, such as protein modification, epigenetic reprogramming, metabolic remodeling, and cytoskeletal rearrangement, in a tissue-specific manner. Dysregulation of DC migration may lead to abnormal positioning or activation of DCs, resulting in an imbalance of immune responses and even immune pathologies, including autoimmune responses, infectious diseases, allergic diseases and tumors. New strategies targeting the migration of distinct DC subsets are being explored for the treatment of inflammatory and infectious diseases and the development of novel DC-based vaccines. In this review, we will discuss the migratory routes and immunological consequences of distinct DC subsets, the molecular basis and regulatory mechanisms of migratory signaling in DCs, and the association of DC migration with the pathogenesis of autoimmune and infectious diseases.

Keywords: dendritic cells; cell migration; chemokine receptor CCR7; inflammation; autoimmune diseases

Cellular \& Molecular Immunology (2021) 18:2461-2471; https://doi.org/10.1038/s41423-021-00726-4

\section{INTRODUCTION}

Dendritic cells (DCs) play crucial roles not only in initiating protective immunity against invading pathogens but also in inducing immune tolerance toward harmless antigens. The wellcoordinated functions of DCs in inflammation and immunity depend on their proper migration to specific destinations. To achieve this, DCs have evolved a complex and dynamic regulatory network involving multiple levels of cellular and molecular interactions for the precise control of DC migration under various immunological or inflammatory conditions [1]. Distinct DC subsets have different mobilization capacities and consequently exert different immunological functions [2]. In particular, CCR7dependent DC migration from peripheral tissues to lymphoid tissues is essential for host defense against pathogens and immune tolerance of harmless self- or nonself-antigens [3]. CCR7 ligation in DCs induces complicated intracellular signaling pathways involving PI3K/AKT, MAPK/NF-KB, HIF-1a, and IRFs, which feedback to regulate the migratory ability and inflammatory response of DCs. Moreover, multiple intracellular mechanisms, such as protein modification, epigenetic reprogramming, metabolic remodeling, and cytoskeletal rearrangement, play potent roles in determining the stability and activity of migratory signaling in DCs. These regulatory networks cooperatively ensure the efficient and effective migration of DCs under homeostatic or inflammatory conditions, leading to a balance between DCdependent immunity and tolerance. In this review, we discuss the routes and consequences of DC subset migration across different tissues. In addition, we highlight the key migratory signaling of
DCs with a summary of underlying regulatory mechanisms. Furthermore, we provide an overview of the pathogenetic effects of dysregulated DC migration in inflammation-related diseases.

\section{MIGRATION ROUTES AND IMMUNOLOGICAL FUNCTIONS}

DCs represent a complicated heterogeneous population of antigen-presenting cells with significant phenotypic heterogeneity and functional plasticity [4]. The precursors of conventional dendritic cells (pre-cDCs), plasmacytoid DCs (pDCs) and monocytes originate from the bone marrow and migrate to lymphoid tissues such as lymph nodes and spleen and nonlymphoid tissues such as skin, lung, and intestines via blood circulation [5]. In peripheral tissues such as the skin, pre-cDCs and monocytes differentiate into immature CDCs and monocyte-derived DCs (moDCs), respectively, and localize in the dermis. Langerhans cells (LCs) are a specialized macrophage-DC hybrid population originating from embryonic progenitors and are localized in the epidermis [6]. These distinct DC subsets follow distinct migratory routes and display different migratory properties and consequently exert variable immunological and inflammatory functions (Fig. 1).

\section{Conventional DCs}

As the major DC types, conventional DCs (cDCs) are characterized by classical dendritic morphology and high expression of $\mathrm{MHC}$ class II molecules and are widespread in tissues and lymph nodes. Immature CDCs act as sentinels of the immune system and are responsible for recognition of a wide range of danger signals

\footnotetext{
${ }^{1}$ National Key Laboratory of Medical Immunology \& Institute of Immunology, Second Military Medical University, Shanghai, China. ${ }^{2}$ Department of Immunology, Center for Immunotherapy, Institute of Basic Medical Sciences, Chinese Academy of Medical Sciences, Beijing, China. ${ }^{凶}$ email: juanliu@immunol.org; caoxt@immunol.org
}

Received: 3 May 2021 Accepted: 9 June 2021

Published online: 23 July 2021 


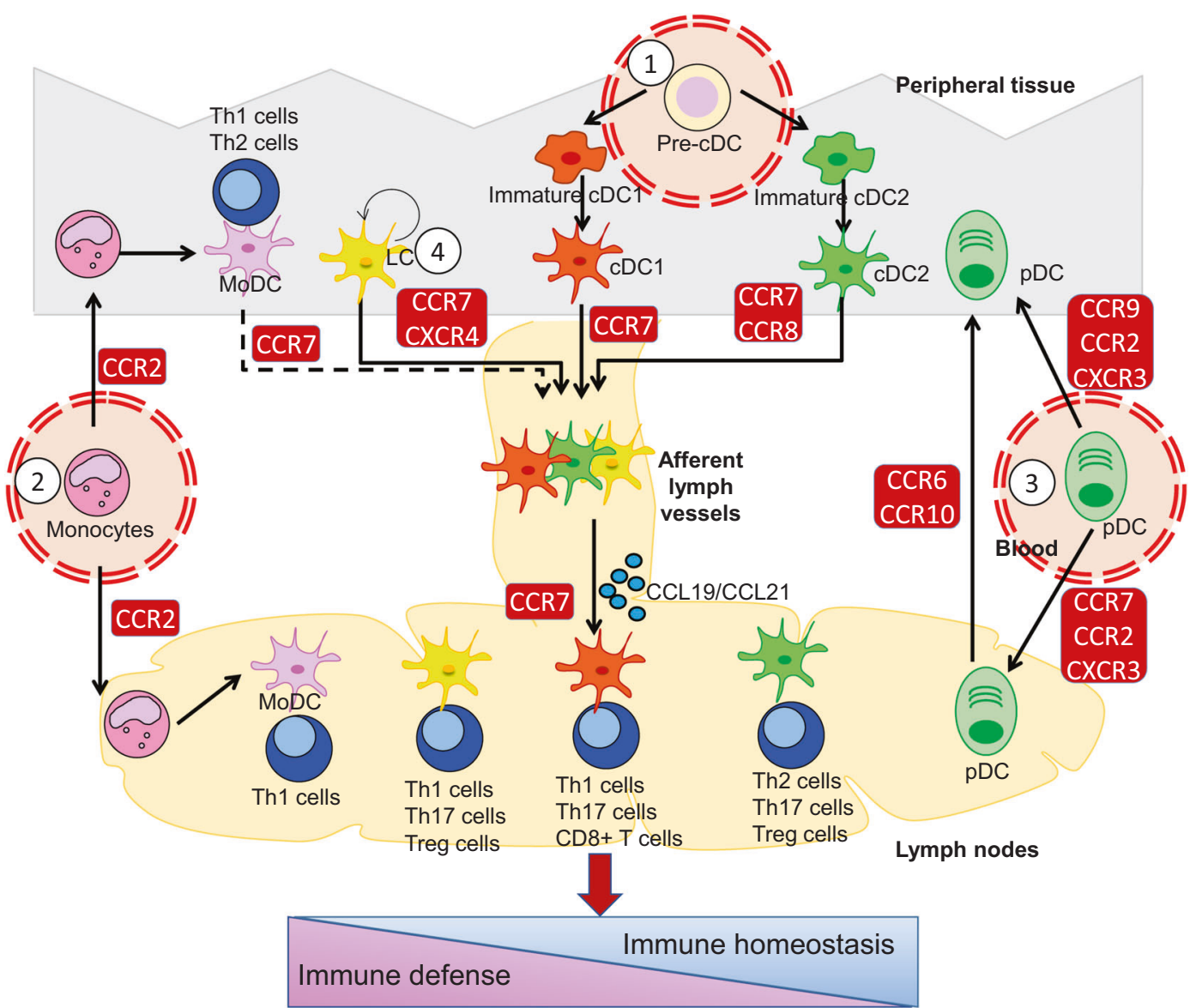

Fig. 1 DC migration in the regulation of immune defense and homeostasis. Dendritic cells can be divided into various subpopulations with significant phenotypic heterogeneity and functional plasticity. The major DC subsets, including conventional DCs (cDCs), monocyte-derived DCs (moDCs), plasmacytoid DCs (pDCs) and Langerhans cells (LCs), follow distinct migratory routes and exhibit different migratory properties and consequently exert various immunological and inflammatory functions. (1) Preconventional dendritic cells (pre-cDCs) give rise to immature $\mathrm{CDCs}(\mathrm{CDC1}$ s and $\mathrm{CDC} 2 \mathrm{~s})$, which undergo maturation and express high levels of CCR7 upon stimulation by pathogenic or inflammatory signals. CCR7 interacts with its ligands CCL19 and CCL21 to guide mature CDC trafficking toward lymph nodes via afferent lymphatics to regulate T-cell immunity. Semimature CDCs also express CCR7 under steady-state conditions and migrate to lymph nodes to induce the activation of regulatory $T$ cells and maintenance of immune tolerance against self-antigens or inhaled and food antigens. $c D C 1 \mathrm{~s}$ potently cross-prime CD8 ${ }^{+}$T cells for viral clearance and activation of the Th1/Th17 response to protect against bacteria. CCR7 and CCR8 mediate CDC2 trafficking to the lymph node parenchyma to initiate a Th2 cell-dependent allergic immune response. (2) Blood Ly6C hi monocytes are recruited to inflamed skin or lymphoid tissues via CCR2 and become monocyte-derived DCs (moDCs), which stimulate Th1 or Th2 responses, contributing to local inflammation. $C X_{3} C R 1^{\text {int }}$ Ly $6 C^{l o}$ moDCs at the lamina propria migrate toward lymph nodes via CCR7 ligation during colon inflammation. (3) Plasmacytoid DC (pDC) recruitment from the blood to the lymph nodes or the small intestine is regulated by CCR7 and CCR9, respectively. CCR2 and CXCR3 are also important for the trafficking and distribution of pDCs. After CCR7mediated extravasation into lymphoid tissues, pDCs are instructed to express CCR6 and CCR10, which mediate their migration to inflamed skin for IFN- $\alpha$ production and facilitate pathogen clearance and local inflammation. (4) LCs are localized in the epidermis and efficiently migrate to skin-draining lymph nodes following inflammatory stimulation in a manner dependent on CCR7 and CXCR4. LCs not only induce T-cell activation during skin inflammation but also mediate the inhibition of T-cell function and the induction of regulatory $\mathrm{T}$ cells

derived from invading pathogens and tissue injuries via pattern recognition receptors (PRRs) [7]. Under stimulation by inflammatory and pathogenic signals, immature DCs become mature CDCs with upregulated expression of $\mathrm{MHC}$ class II, costimulatory molecules and the chemokine receptor CCR7. CCR7 interacts with its ligands CCL19 and CCL21 to guide CDC trafficking toward lymph nodes via afferent lymphatics [8-10]. DCs follow CCL21 gradients in the subcapsular sinus (SCS) of the lymph nodes to migrate along with CCL21 concentration gradients, which are shaped by the expression of the atypical chemokine scavenger receptor ACKR4 on the outer wall (ceiling) of the SCS [11]. After crossing the inner wall (floor) of the SCS, DCs finally enter the Tcell area via CCR7 ligation, where they can interact with naïve T cells [12]. Immature DCs also undergo spontaneous maturation and upregulation of CCR7 in the absence of obvious inflammatory stimuli. These so-called semimature DCs express CCR7 under steady-state conditions and migrate to lymph nodes for the maintenance of immune tolerance against self-antigens or inhaled and food antigens [13-15]. The autoimmune phenotype in CCR7deficient mice, as characterized by extensive lymphocyte infiltration of multiple organs and abundant autoantibodies in blood, highlights the importance of CCR7 signaling in the maintenance of immune tolerance $[16,17]$. In addition to CCL19 and CCL21, many other types of chemokines and cytokines are involved in the regulation of DC migration. We previously cloned and characterized MIP2 $\gamma$ (macrophage inflammatory protein-2 gamma), also known as CXCL14, which is constitutively and widely expressed in most normal tissues, recruits neutrophils and DCs via chemoattractants, and regulates the differentiation of $\mathrm{CD}_{14}^{+} \mathrm{DC}$ precursors into Langerhans cell-like cells [18-20].

CDCs can be further divided into CDC1 and CDC2 subpopulations. CDC1s are characterized by the surface markers XCR1 and CD103 
and developmentally depend on the transcription factors IRF8 and Batf3. $c D C 2 s$ are a heterogeneous group expressing the surface marker CD11b (but not XCR1) and are developmentally dependent on the transcription factor IRF4. While $\mathrm{CDC} 1 \mathrm{~s}$ are capable of inducing $\mathrm{CD}^{+}{ }^{-}$-cell activation and Th1 and Th17 skewing, CDC2s potently induce Th2 and Th17 skewing (Fig. 1) [1]. The Th2-skewing CDC2 subset is further dependent on the transcription factor KLF4, while the Th17-skewing CDC2 subset (which can also express CD103) does not require KLF4 [21]. Although both CDC1s and CDC2s are capable of capturing antigens and migrating to draining lymph nodes for the initiation of adaptive immune responses, they differ in their responsiveness to migratory and inflammatory signals in the microenvironment and their capacity to induce T-cell activation or regulation.

Lung $\mathrm{CD}_{103^{+}} \mathrm{CDC1s}$ transport influenza viral antigens to the lymph nodes for efficient cross-priming of $\mathrm{CD}^{+} \mathrm{T}$ cells, which is critical for viral clearance $[22,23]$, as well as induction of Th1/Th17 responses and protection against pulmonary Chlamydia muridarum infection [24]. $\mathrm{CD} \mathrm{a}^{+} \mathrm{DC}$ expression of the lectin family member Siglec-G can functionally inhibit DC cross-presentation to antigen-specific CTLs by impairing formation of the MHC class Ipeptide complex [25]. During influenza infection, CDC1s can promote S1PR expression on cytotoxic T lymphocytes (CTLs) to facilitate CTL migration toward lymph nodes and express high levels of IL-15 to support CTL survival and activity at the site of infection [26]. Skin CD103 ${ }^{+}$CDC1s are important for the crosspresentation of self- and nonself-antigens to $\mathrm{CD}^{+} \mathrm{T}$ cells and efficiently promote CTL responses against keratinocyte-derived antigens or viruses $[27,28]$. Interestingly, uterine $\mathrm{CD} 103^{+} \mathrm{DC}$ subsets have been shown to induce a tolerogenic response of Foxp $^{+} \mathrm{CD}_{25} 5^{+}$Treg cells upon Chlamydia trachomatis infection [29].

CDC2s express lower levels of CCR7 after allergen exposure and are capable of equally upregulating CCR7 in response to PAMP exposure. Various additional signals have been found to initiate or support CDC2 migration toward lymph nodes. Chemokine signals mediated by CCR8 and its ligand CCL8 from macrophages can mediate $\mathrm{CD} 301 \mathrm{~b}^{+} \mathrm{DC}$ trafficking to the lymph node parenchyma to initiate a Th2 cell-dependent allergic immune response [30]. Colony-stimulating factor 1 (CSF1) secreted from airway epithelial cells selectively upregulates CCR7 expression in $\mathrm{CSF} \mathrm{R}^{+} \mathrm{CDC} 2 \mathrm{~s}$, contributing to Th2 cell-mediated allergic lung inflammation [31]. Inhibition of the CSF1-CSF1R signaling pathway has been shown to effectively block CDC2 migration and allergen sensitization and consequently abolish chronic allergenic lung inflammation in a murine model of chronic asthma, suggesting CSF1/CSF1R as a promising new target for the treatment of allergic asthma [32]. In addition, substance $\mathrm{P}$, a type of neuropeptide produced by allergen-activated sensory neurons, induces $\mathrm{CD}_{301 \mathrm{~b}^{+}} \mathrm{CDC} 2$ migration to the lymph nodes to prime Th2 cell differentiation, indicating an interesting link between allergen-induced acute activation of the sensory nervous system and chronic allergic inflammation [33].

\section{Monocyte-derived DCs}

Monocyte-derived DCs (moDCs) represent an inflammatory DC subpopulation induced by various inflammatory stimuli and exist in various lymph nodes and tissues. Blood Ly6C ${ }^{\text {hi }}$ monocytes are recruited to the inflamed skin via CCR2 to become monocyte-derived DCs (moDCs), which are capable of activating protective Th1 responses at the site of infection [34]. Although skin moDCs are able to migrate to the auricular lymph nodes in a CCR7-dependent manner upon DNFB-induced skin inflammation, their migratory capacity is very poor compared to that of dermal $C D 11 b^{+} \mathrm{cDCs}$ [35]. Similarly, despite producing proinflammatory chemokines and mediating Th2 cell immunity to house dust mite allergens in the lung, $\mathrm{CD}_{11} \mathrm{~b}^{+}$moDCs are the least prevalent DC population among migratory DCs within the mediastinal lymph nodes, indicating that lung moDCs are also poorly migratory [36]. In the inflamed colon, Ly6 $C^{\text {hi }}$ monocytes are recruited to the lamina propria via CCR2 and gradually differentiate into $C X_{3} C R 1^{\text {int }}$ Ly6 $6 C^{\text {lo }}$ moDCs with the capacity for antigen capture, presentation and T-cell priming, which express CCR7 for egression from the colonic lamina propria toward the mesenteric lymph nodes, contributing to colon inflammation [37]. Therefore, inflammatory blood-derived moDCs play important roles in mediating various types of tissue inflammation by producing inflammatory cytokines and stimulating T-cell activation, but their capacity for subsequent emigration toward lymph nodes is regulated differently.

Notably, inflammatory monocytes can be recruited into lymph nodes directly from the blood via CCR2 to become $\mathrm{CD} 11 \mathrm{c}^{+} \mathrm{CD} 11 \mathrm{~b}^{\mathrm{hi}} \mathrm{Gr}-1^{+}$inflammatory $\mathrm{DCs}$, which potently activate Th1 responses by producing IL-12p70 [38]. CXCL10-producing inflammatory monocytes infiltrate the interfollicular regions (IFRs) of lymph nodes from blood following incomplete Freund's adjuvant (IFA)-containing immunization and promote Th1skewed niche development in the lymph nodes [39]. In addition, gram-negative bacterial stimulation or LPS can stimulate moDC migration from blood and accumulation in lymph nodes, and these moDCs show antigen cross-presentation activity and migrate to T-cell areas via L-selection and CCR7 [40]. Thus, it will be intriguing to delineate the specific functions and activities of tissue-derived moDCs and blood-derived moDCs in shaping immune responses in the lymph nodes. One recent study suggests that $\mathrm{CDC} 2 \mathrm{~s}$ may acquire the IRF8 features of $\mathrm{CDC} 1 \mathrm{~s}$ and the Fc receptor CD64 feature of MoDCs and contribute to the antigen processing function of MoDCs during inflammation. It will be necessary to carefully clarify the potential overlap in markers and functions among $\mathrm{CDC} 1 \mathrm{~s}, \mathrm{CDC} 2 \mathrm{~s}$, and MoDCs under homeostatic and inflammatory conditions [41].

\section{Plasmacytoid DCs}

Plasmacytoid DCs (pDCs) are potent producers of type I interferons and are important for the host antiviral immune response. pDCs are commonly distributed in peripheral blood and lymphoid organs and have unique migratory properties. The recruitment of pDCs from the blood to the lymph nodes via high endothelial venules is regulated by CCR7 [42], ChemR23 [43], CXCR3 [44, 45], L-selectin, and E-selectin [46]. pDCs also constitutively migrate into the splenic white pulp in a manner dependent on the chemokine receptors CCR7 and CXCR4 [47]. Notably, after CCR7-mediated extravasation into lymphoid tissues, pDCs are induced to express CCR6 and CCR10, which further mediate their migration to inflamed skin in response to CCL20 and CCL27/CCL28, respectively. CCR6-dependent pDC homing to the epithelium contributes to the production of IFN-a and facilitates pathogen clearance and local inflammation [48]. CpGtriggered migration of $\mathrm{pDCs}$ from the skin to the draining lymph node via the lymphatics has been observed in pigs and sheep, yet the corresponding chemokine receptors involved in this process and their immunological consequences remain to be identified [49].

CCR9 is required for PDC homing from blood to the small intestine under homeostatic and inflammatory conditions. CCR9dependent accumulation of intestinal pDCs consequently promotes lamina propria CDC mobilization $[50,51]$. In addition, pDCs express mucosal addressin cell-adhesion molecule-1 (MAdCAM-1) and $\beta 7$ integrin, which ensures the efficient migration of pDCs into the intestinal intraepithelial compartment [52]. Interestingly, the microbiota enhances homeostatic trafficking and peripheral distribution of $\mathrm{CCR}^{+}$pDCs by inducing homeostatic levels of the chemokine CCL2 produced by mononuclear phagocytes [53]. Therefore, a complex network of chemokines, adhesive molecules, microbiota, immune and nonimmune cells cooperatively regulates pDC trafficking and distribution to orchestrate intestinal homeostasis and inflammation. 


\section{Langerhans cells}

Langerhans cells (LCs) exhibit mixtures of characteristics from macrophages (self-replenishment) and DCs (migration and T-cell stimulation). LCs are mainly localized in the epidermis and quickly migrate to skin-draining lymph nodes following inflammatory stimulation in a manner dependent on CCR7 [54]. After arriving at the draining lymph nodes, LCs not only induce immune activation but also mediate the inhibition of T-cell function and the induction of regulatory $T$ cells in a context-dependent manner. A recent study on natural CXCR4 mutants harboring a gain of function that causes warts, hypogammaglobulinemia, infections, and myelokathexis (WHIM) syndrome, a rare immunodeficiency associated with high susceptibility to the pathogenesis of human papillomavirus (HPV), indicated that proper CXCR4 signaling directs efficient migration of both LCs and DCs from skin to lymph nodes and determines their activation state. Therefore, targeting CXCR4dependent LC and DC migration could be considered a potential therapeutic strategy for CXCR4-associated diseases such as WHIM syndrome [55].

\section{SIGNALING TRANSDUCTION OF DC MIGRATION}

While the innate immune signaling triggered by PRRs such as Tolllike receptors (TLRs) and Nod-like receptors (NLRs), which recognize a wide variety of pathogenic components, or nuclear acid sensors such as RIG-I-like receptors (RLRs) and cyclic GMPAMP (cGAMP) synthetase (cGAS), which detect self- or nonselfnucleic acids, has been intensively investigated for its downstream pathways and functional roles in inflammatory activation [56], chemokine receptor-induced intracellular signaling is less well understood. The most important chemotactic response for DC migration is mediated by CCR7, a G protein-coupled receptor that recognizes the chemokine ligands CCL19 and CCL21. CCL21 is constitutively expressed by lymphatic endothelial cells and is essential for guiding DCs to the lymph nodes. Two mouse genes encode functional CCL21 variants, CCL21-Ser and CCL21-Leu. CCL21-Ser is expressed in both secondary lymphoid organs and lymphatics, whereas CCL21-Leu is expressed only in the lymphatic vessels of nonlymphoid organs. Thus, CCL21 isoforms are present in peripheral tissues to promote DC entry into draining lymphatics. CCL19 is expressed by stromal cells within the secondary lymphoid organs but not by lymphatics [57, 58]. Although CCL19 and CCL21 have similar binding affinities for CCR7, CCL19 is more potent in recruiting $\beta$-arrestin and inducing clathrindependent desensitization and endocytosis of CCR7 into endosomes [59]. Preferential DC migration toward CCL21 over CCL19 was observed in a 3D environment, probably due to a stronger binding affinity to extracellular matrix proteoglycans by the positively charged $C$ terminus of $\operatorname{CCL} 21[60,61]$. It remains unclear how CCR7 differentially recognizes chemotactic signals from CCL19 or CCL21 and how these different molecular events regulate downstream signal transduction and DC-driven immune responses.

Complex signaling pathways involving PI3K/AKT, MAPK/NF-KB, HIF-1a, and IRFs have been shown to be activated by CCR7 and play regulatory feedback roles in DC migration in a contextdependent manner. As DC migration is closely related to other aspects of DC biology, such as maturation and activation, both spatially and temporally, the crosstalk among distinct signaling pathways initiated by PRRs or chemokine receptors is essential for a coordinated inflammatory and migratory response during the development of immunity and tolerance.

\section{Phosphoinositide 3-kinase/AKT kinase pathway}

Phosphoinositide 3-kinase (PI3K) exerts widespread functions in modulating variable aspects of immune cell development and chemotaxis, which is critical for the orchestration of cellular responses and immune homeostasis. CCR7 stimulation induces significant activation of PI3K and its downstream effector Akt [62-64]. CCR7 also induces antiapoptotic signaling in mature DCs via the $\mathrm{PI} 3 \mathrm{~K} / \mathrm{AKT}$ and NF-KB pathways [62]. Interestingly, Fas ligation induces the production of CXC and CC chemokines by DCs via the ERK pathway, resulting in enhanced chemoattraction of neutrophils and T cells, implying the nonapoptotic function of Fas in immune cell chemotaxis [65]. The PI3K family consists of three main groups of enzymes (classes I, II, and III) that are characterized on the basis of their substrate phosphoinositides [66]. Mice deficient in the $\gamma$ isoform (class IB) of PI3K display severely impaired DC migration in response to the chemokines CCL3, CCL5, and CCL19 and an attenuated response during contact hypersensitivity and delayed-type hypersensitivity reactions to both FITC and DNFB [67]. In lymphocytes, class IA PI3Ks are important in regulating basal lymphocyte motility, and p85 regulatory subunit expression is required for B cell morphology independent of PI3K catalytic function [68]. Thus, the contributions of distinct PI3K members to cell chemotaxis and migration are regulated in a cell-type-selective manner.

The actin-bundling protein palladin was shown to be an Akt1specific substrate that modulates breast cancer cell invasive migration [69]. However, the molecular targets of PI3K/AKT in the regulation of immune cell migration remain elusive. In addition, PI3K/AKT signaling influences intracellular metabolic events via multiple pathways, for example, by activating sterol-regulatory element-binding proteins (SREBPs), essential transcriptional regulators of lipid metabolism [70], and by activating AS160, the key enzyme regulating glucose uptake [71]. Whether the interaction between PI3K/AKT signaling and metabolism conversion affects DC migration and the consequent immune responses remains to be unveiled.

\section{Mitogen-activated protein kinase/nuclear factor-кB pathway} The mitogen-activated protein kinase (MAPK)/nuclear factor-kB (NF-KB) pathway is critical for TLR-induced DC maturation and activation via the induction of a series of inflammatory cytokines, such as IL-1, IL-6, and TNF. The activation of MAPK/NF-KB signaling is tightly controlled by multiple intrinsic negative regulators, such as the ubiquitin-editing enzyme $A 20$, the $E 3$ ligase $A R I H 2$, and the Rhomboid protease RHBDD3, to avoid aberrant systemic inflammation $[72,73]$. CCR7 stimulation leads to $\beta$-arrestin recruitment and MAPK activation, which are important for DC chemotaxis and activation [74, 75]. CCL19 and CCL21 not only drive the migratory capacity of DCs but also enhance the T-cell-stimulating function of mature DCs via upregulation of the costimulatory molecules CD86 and $\mathrm{CD} 40$ and promotion of the production of proinflammatory cytokines such as IL-1 $\beta$, TNF, and IL-12 [76]. CCR7 ligands have also been shown to increase the antigen uptake of mature DCs by activating the Rho guanosine triphosphatases Rho, Rac, and Cdc42 [77]. However, canonical NF-kB target genes, such as $\|1 b\| 1 a,, \| 6$, $1112 b$, and Tnfsfla, are suppressed in migratory $\mathrm{CDCs}$, indicating context-specific networks of NF-KB-regulated genes during DC maturation and migration [78]. Therefore, MAPK/NF-KB pathway activation during DC migration is strictly dependent on complex molecular networks involving upstream signaling regulators and downstream-specific gene networks, as well as their interacting transcriptional coactivators or corepressors.

NF-KB-dependent inflammatory signaling feedback regulates CCR7-mediated DC migration via several mechanisms. DCs upregulate the expression of MHC-II, costimulatory molecules and CCR7 on the cell surface and enhance their migratory ability during LPS/MAPK/NF-KB pathway-induced maturation [79]. Full induction of CCR7 is dependent on immediate activation of the IKK/NF-KB cascade and a secondary AP-1 response [80]. Mice deficient in IKK $\beta$, an upstream regulator of NF-KB, display impairment in homeostatic DC migration and spontaneous development of autoimmune diseases, indicating a role of the noncanonical IKK $\beta$-dependent pathway of NF-KB signaling in the regulation of homeostatic $D C$ migration and the maintenance of 
immune tolerance [78]. This effect has been thought to depend on the putative NF-KB-regulated gene Fscn1, which positively regulates the migration of mature DCs into lymph nodes by enhancing membrane protrusive activity and podosome disassembly [81]. In addition, complete or DC-specific deletion of MyD88, an essential adaptor protein of TLR- and TNF-triggered signaling, results in a reduction in the steady-state migration of CD103 + DCs into draining mesenteric lymph nodes. MyD88dependent steady-state DC migration is independent of inflammatory cytokines such as IL-18 and TNF but is required for optimal CCR9 induction and CD62L downregulation in T cells [82]. Thus, MyD88/NF-KB activation is unexpectedly involved in steady-state DC migration and the maintenance of immune tolerance, and the underlying mechanisms remain to be investigated.

We previously demonstrated that TLR4 ligation by LPS promotes CT-26 colon cancer cells to produce the chemokine CCL20 and increases the chemoattraction of immature DCs via autocrine CCL20 [83]. Cyclosporin A, a powerful immunosuppressive drug, impairs DC migration from the skin to secondary lymphoid organs by regulating chemokine receptor expression and inhibiting cyclooxygenase-2 (COX-2) expression via inhibition of MAPK/NFKB signaling pathways [84]. Similarly, triptolide, an active component of the Chinese herb Tripterygium wilfordii, impairs CCL19-mediated DC migration toward secondary lymphoid organs by inhibiting CCR7 and COX-2 expression by targeting the PI3K/Akt and NF-KB pathways, providing a potential mechanistic explanation for the anti-inflammatory activities of triptolide [85]. Triptolide also impairs DC-mediated chemoattraction of neutrophils and T cells by suppressing DC production of CC and CXC chemokines, including MIP-1 1 , MIP-1 $\beta$, MCP-1, and RANTES, in response to LPS through inhibition of Stat3 phosphorylation and NF-KB activation [86]. These findings highlight the importance of modulating the NF-KB pathway to affect DC migration in antitumor immune therapy. The more detailed function of NF-KB and its contextspecific target genes in the regulation of CCR7-dependent DC migration under inflammatory conditions or within tumor microenvironments remain to be investigated.

\section{Hypoxia inducible factor 1-alpha}

Hypoxia inducible factor 1-alpha (HIF-1a) is a central transcription factor controlling cell responses to hypoxic stress and plays essential roles in various aspects of innate and adaptive immune responses [87, 88]. Hypoxia plays important roles in innate immunity both under steady-state (physiologic hypoxia) and during active inflammation (inflammatory hypoxia) and contributes fundamentally to inflammatory and immune responses [89]. HIF-1a has been increasingly shown to support DC migration and function via various mechanisms $[90,91]$. Hypoxia-generated DCs show increased migratory ability, which is dependent on HIF-1a, as evidenced by the reduced migration to CCL19 of HIF-1adeficient DCs compared with wild-type DCs under hypoxic conditions [92]. DCs generated under hypoxia display a distinguishable migratory phenotype, including enhanced mRNA expression of the chemokine receptors CCR3, CX3CR1 and CCR2 and decreased mRNA expression of chemokines such as CCL18, CCL23, CCL26, CCL24, and CCL14, and functionally demonstrate a stronger chemotactic response to CCR2 and CXCR4 agonists [93]. Deletion of HIF-1a in myeloid cells results in impaired inflammatory responses during induced arthritis, in association with defective macrophage aggregation, invasion and motility, as well as severely impaired glycolysis and energy generation [94]. Our recent study determined that CCR7 stimulation enhances the expression of the HIF-1a-dependent glycolytic gene LDHA and the production of glycolytic NAD ${ }^{+}$, the feedback of which supports $\mathrm{DC}$ migration by maintaining $\mathrm{F}$-actin polarization and polymerization [95]. Therefore, HIF-1a serves as a key regulator of DC migration and inflammation by coordinating intracellular glycolytic reprogramming and cytoskeletal rearrangement.

\section{IFN regulatory factors}

Several IFN regulatory factor (IRF) proteins have been shown to regulate DC migration, such as IRF4 and IRF8. IRF4 and IRF8 are expressed in $C D 11 b^{+}$and $C D 11 b^{-}$DC subsets separately and are required for the generation of the respective DC subsets [96-98]. IRF4-deficient mice show reduced CCR7 expression and defective migration of dermal CD11 $\mathrm{b}^{+} \mathrm{DCs}$ to cutaneous lymph nodes both under homeostasis and during skin inflammation, suggesting a crucial role of IRF4 in supporting the migration of dermal CD11 $\mathrm{b}^{+}$ DCs [99]. IRF4 is also required for the survival of intestinal $\mathrm{CD}_{103}{ }^{+} \mathrm{CD} 11 \mathrm{~b}^{+} \mathrm{DCs}$, which drive Th17 cell differentiation by secreting IL-6 [100, 101]. Interestingly, higher levels of IL-12 production, increased IFN- - -producing Th1 cells and enhanced effective clearance of parasites after infection with $L$. major were observed in DC-specific IRF4-deficient mice, suggesting an inhibitory role of IRF4 in regulating IL-12 production of DCs and Th1-induced immune responses against parasites [102]. IRF4 and IRF8 have been found to directly target and activate the genes encoding CD80, CD86 and CCR7 in migratory DCs, and IRF4 preferentially activates genes that encode proteins related to MHC class II antigen presentation [103]. Notably, given the role of IRFs as lineage-defining transcription factors, it is difficult to separate their roles in DC migration versus development. It is intriguing to further explore the molecular mechanisms underlying the distinctive activity of different IRFs in the regulation of DC migration and development.

\section{MOLECULAR REGULATION OF DC MIGRATION}

To ensure the most beneficial outcome of DC migration in immunity and tolerance, multiple levels of intracellular regulators are employed to modulate the signaling pathways induced by chemokine/chemokine receptor interactions. These regulatory networks occur at the transcriptional or translational level to regulate the adhesive or chemotactic ability of DCs, contributing to the fine-tuned control of DC-dependent inflammation and immunity (Fig. 2).

\section{Protein modification}

Conventional posttranslational modifications (PTMs), such as phosphorylation and ubiquitination, are essential for CCR7dependent signal transduction. CCL19 and CCL21 stimulation induces the phosphorylation of CCR7 [75], $\beta$-arrestin [104], MAPK/ ERK, p38 and JNK [105] successively, which is crucial for DC chemotaxis and migration. Oligomerization of CCR7 induced by the inflammatory mediator prostaglandin E2 $\left(\mathrm{PGE}_{2}\right)$ and phosphorylation of oligomeric CCR7 by Src are necessary for the migration of DCs and T cells [106]. Internalized CCR7 recycles back to the plasma membrane to replenish the cell surface with fresh CCR7 for chemokine sensing $[107,108]$. The $\beta$-arrestin-mediated internalization of CCR7 into endosomes triggers an endomembrane signaling complex involving Vav1 and Rac1, leading to lamellipodia formation and sustained DC migration [109]. In addition, polysialylation of CCR7 is essential for recognition of CCL21 and therefore controls CCR7-mediated DC migration. Mice deficient in the polysialyltransferase St8sia4 show disrupted immune homeostasis due to an abrogated DC migration ability. Mechanistically, recognition of polysialic acid by the $C$ terminus of CCL21 releases CCL21 from selfinhibition, thus facilitating CCR7 coupling with CCL21 [110]. It will be intriguing to investigate whether other types of PTMs, such as methylation, acetylation, SUMOylation and succinylation, which potently regulate PRR-dependent innate immune signaling [111], also participate in the regulation of migratory signaling triggered by CCR7 or other chemokine receptors.

\section{Epigenetic reprogramming}

Epigenetic factors such as DNA methylation changes, histone modifications and noncoding RNAs play potent roles in the 


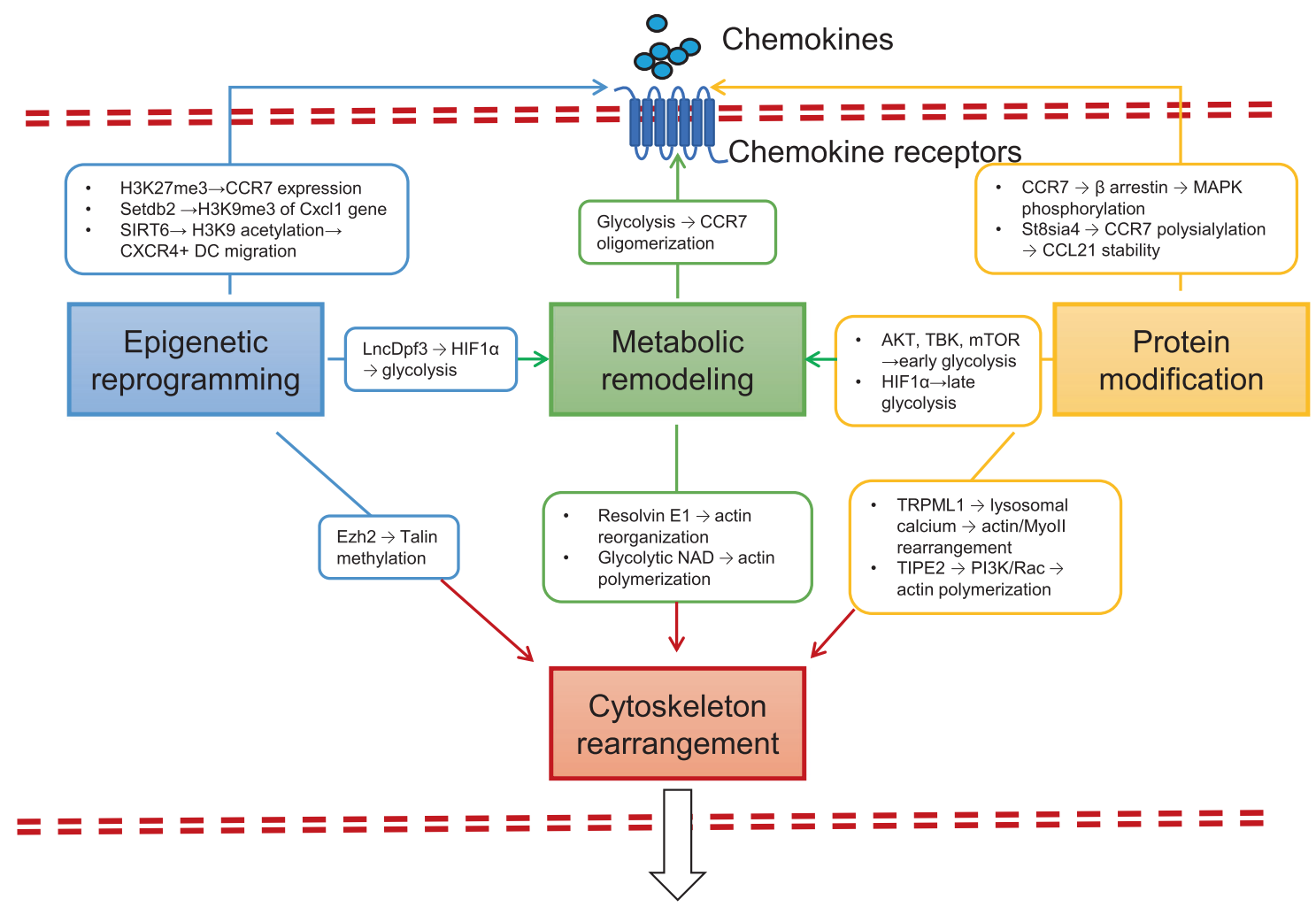

\section{DC chemotaxis and migration}

Fig. 2 Molecular regulation of DC migration. Multiple levels of intracellular regulators are employed to modulate the signaling pathways induced by chemokines to ensure the most beneficial outcome of DC migration in the regulation of immunity and tolerance. (1) Protein modification (shown in yellow boxes and arrows). CCL19 and CCL21 stimulation induces the phosphorylation of CCR7, $\beta$-arrestin, MAPK/ERK, p38 and JNK successively, which is crucial for DC chemotaxis and migration. Polysialylation of CCR7 is essential for recognition of its ligand CCL21 and therefore controls CCR7-mediated DC migration. (2) Epigenetic reprogramming (shown in blue boxes and arrows). Migratory CDCs and nonmigratory moDCs show different levels of H3K27me3 modifications at the CCR7 gene locus. Setdb2 induces the generation of $\mathrm{H} 3 \mathrm{~K} 9 \mathrm{me} 3$ (a repressive marker) at the Cxcl1 gene promoter, leading to reduced neutrophil infiltration and inhibited host defense against bacterial superinfection. SIRT6 promotes CXCR4 ${ }^{+}$DC migration to the afferent lymph nodes via its effects on monitoring H3K9 acetylation. Ezh2 directly mediates methylation of the cytoplasmic integrin adaptor talin, disrupting the binding of talin to F-actin, thereby promoting the extravasation and motility of DCs under inflammatory conditions. The long-noncoding RNA Inc-Dpf3 directly binds to the transcription factor HIF- $1 \alpha$ and suppresses HIF-1 $\alpha$-dependent transcription of the glycolytic gene Ldha, thus inhibiting DC glycolytic metabolism and migratory capacity. (3) Metabolic remodeling (shown in green boxes and arrows). Glycolytic metabolism is essential for CCR7 oligomerization and DC migration, and glycolytic NAD ${ }^{+}$supports $\mathrm{DC}$ migration by maintaining F-actin polarization and polymerization. Resolvin E1 inhibits DC motility and migration and attenuates the contact hypersensitivity response by disrupting actin polymerization. (4) Cytoskeleton rearrangement (shown in dark red boxes and arrows). Actin polymerization and retrograde flow at the front and actinomyosin contraction at the rear determine cell polarity and provide the driving forces of DC migration. The phosphoinositide transferase protein TIPE2 plays dual roles in signaling regulation by inhibiting Rac-dependent actin polymerization at the rear but enhancing PI3K-dependent actin polymerization at the front, thus facilitating cytoskeleton remodeling and leading-edge formation. The ionic channel TRPML1 (transient receptor potential cation channel, mucolipin subfamily, member 1) is activated for lysosomal calcium release, leading to rearrangement of the actin-based motor protein myosin II at the cell rear, promoting fast and directional migration

development and activation of innate immune cells via transcriptional regulation of gene expression $[112,113]$. Significant differences in the repressive H3K27me3 (trimethylation of histone 3 lysine 27) levels at the CCR7 gene locus were observed between migratory CDCs and nonmigratory moDCs, indicating the involvement of epigenetic modifications in determining the migratory capacity of distinct DC subsets [114]. The lysine methyltransferase SET domain bifurcated 2 (Setdb2), which is upregulated upon viral infection, induces H3K9me3 (a repressive marker) of $\mathrm{Cxcl} 1$ gene promoters, leading to reduced neutrophil infiltration and inhibited host defense against bacterial superinfection [115]. The $\mathrm{NAD}^{+}$-dependent deacetylase Sirtuin 6 (SIRT6) contributes to the ability of $\mathrm{CXCR4}^{+}$DCs to migrate to the afferent lymph nodes during experimental autoimmune encephalomyelitis development, probably via its effects on monitoring H3K9 acetylation [116]. We recently showed that intracellular HSP70L1 (heat shock protein 70-like protein) maintains the repressive H3K27me3 and
H2AK119Ub1 modifications at the promoter regions of costimulatory MHC and STAT3 genes of DCs by inhibiting the recruitment of the absent, small, or homeotic 1-like (ASH1L) methyltransferase, thus inhibiting DC maturation and function [117-119].

Long-noncoding RNAs (IncRNAs) have emerged as critical regulators of innate immunity and inflammation and regulate these processes via multiple mechanisms, such as RNA-DNA, RNARNA or RNA-protein interactions [120]. We previously identified Inc-DC, a novel IncRNA exclusively expressed in human cDCs, as potently regulating $D C$ differentiation and activation via direct binding to cytoplasmic STAT3 [121]. The IncRNA BCAR4 (breast cancer antigen-resistance 4) has been shown to mediate epigenetic regulation of CCR7 signaling by activating a transcriptional program that promotes tumor cell migration, but its relevance to DCs remains unclear [122]. While sufficient DC migration is necessary for the rapid induction of protective 
immunity, timely termination of DC trafficking is equally important for the prevention of unwanted inflammatory damage. Our recent study identified a new IncRNA, Inc-Dpf3, as a feedback inhibitor of DC migration and the inflammatory response. Mechanistically, IncDpf3 directly binds to the transcription factor HIF-1a and suppresses HIF-1a-dependent transcription of the glycolytic gene Ldha, thus inhibiting DC glycolytic metabolism and migratory capacity [95]. Inc-Dpf3 bears N6-methyladenosine (m6A) modification for its degradation at steady-state, and CCR7 stimulation upregulates Inc-Dpf3 by relieving m6A-dependent RNA degradation. We also found that RNA methyltransferase Mettl3-mediated m6A methylation promotes activation and cytokine production of DCs by enhancing CD40, CD80 and the TLR4 signaling adaptor Tirap and strengthening TLR4/NF-KB signaling [123]. These findings shed new light on the epigenetic regulation of DC migration and activation by noncoding RNAs and RNA modifications. Taken together, these findings show that epigenetic enzymes or regulators participate in the regulation of innate immune cell migration by targeting either histone or nonhistone substrates, leading to transcriptional or translational regulation of signal transduction and metabolic or cytoskeletal reprogramming.

\section{Metabolic remodeling}

A variety of metabolic enzymes, sensors or intermediates play potent roles in coordinating cellular immunological responses during inflammation and infection, leading to variable biological and pathological consequences [124]. DCs with different statuses or varied DC subsets demonstrate distinct metabolic characteristics that influence their inflammatory and immunological functions [125]. Mice deficient in ATP-binding cassette transporters $A 1$ and $\mathrm{G} 1$ (Abca1/g1), the key enzyme mediating cholesterol efflux from immune cells, develop a systemic autoimmune phenotype including enlarged lymph nodes and glomerulonephritis. Abca1/g1 deletion resulted in increased splenic CD $11 \mathrm{~b}^{+}$ DCs (which displayed cholesterol accumulation, inflammasome activation and higher expression of the GM-CSF receptor, and enhanced inflammatory cytokine secretion) and consequently enhanced T-cell activation and polarization [126]. This study indicated the importance of DC cholesterol stability in maintaining DC-dependent immune homeostasis. In addition, mice deficient in apolipoprotein A-I (which are characterized by diminished circulating high-density lipoprotein) exhibited increased severity of antigen-induced arthritis in association with enhanced DCdependent Th1 and Th17 autoimmune responses [127]. Profound changes in lipid composition and membrane fluidity occur during DC maturation, which likely influence the DC migration process and DC-T-cell interaction [128]. A lipid mediator derived from $\omega 3$ polyunsaturated fatty acids, resolvin E1, was shown to abrogate leukotriene B4-dependent activation of actin filament reorganization and Cdc42/Rac1-dependent DC motility, thus attenuating cutaneous acquired immune responses [129]. It will be intriguing to investigate whether other components of the lipid and cholesterol pathways affect the migratory ability of DCs.

TLR stimulation induces rapid glycolysis, which is required for anabolic demands of DC activation [130, 131]. Recent evidence indicates that glycolytic metabolism is essential for DC migration to draining lymph nodes because it maintains DC motility and CCR7 oligomerization [132]. While AKT, TBK, and mTOR are involved in the early induction of glycolysis, HIF-1a is required for the late phase of glycolysis. Glycolytic $\mathrm{NAD}^{+}$supports $\mathrm{DC}$ migration by maintaining F-actin polarization and polymerization [95]. The respective contributions of the early and late phases of glycolysis to DC migration and function remain to be further identified.

\section{Cytoskeleton rearrangement}

The cytoskeleton is important for numerous cellular processes because it regulates cell morphology, structure, movement and function. Actin polymerization and retrograde flow at the front of the cell, as well as actinomyosin contraction at the rear of the cell jointly determine cell polarity and provide the driving forces of cell migration [133]. The small GTPase Cdc42 was shown to be required for DC migration by coordinating leading-edge formation [134]. The guanine nucleotide exchange factor Dock8 (dedicator of cytokinesis 8 ) is required for the ameboid migration of DCs because it activates small GTPase Cdc42 activators [135, 136]. Dock8-deficient mice exhibit reduced DC migration to skin-draining lymph nodes and impaired germinal center antibody production [137], outlining the importance of the cytoskeleton network in mediating DC migration and DC-dependent immune response. Moreover, the histone lysine $\mathrm{N}$-methyltransferase enhancer of zeste homolog 2 (Ezh2) has been shown to directly mediate methylation of the cytoplasmic integrin adaptor talin, disrupting the binding of talin to F-actin and thereby promoting the extravasation and motility of DCs under inflammatory conditions [138]. In addition, TIPE2 (tumor necrosis factor-alphainduced protein 8-like 2), a phosphoinositide transferase protein, contributes to leukocyte polarization and infiltration during experimental autoimmune encephalomyelitis (EAE) development. TIPE2 inhibits Rac-dependent actin polymerization at the rear but enhances PI3K-dependent actin polymerization at the front, thus facilitating cytoskeleton remodeling and leading-edge formation [139].

Rearrangement of cytoskeletal networks not only generates the locomotion force of DC chemotaxis and movement but also plays a regulatory role in DC functions, including antigen processing, inflammatory cytokine production and chemotactic migration [140]. Immature DC migration depends on two actin pools, a RhoA-mDia1-dependent actin pool located at the rear, which is important for forward locomotion, and a Cdc42-Arp2/3-dependent actin pool present at the front, which limits cell migration but promotes antigen capture. Upon LPS-induced DC maturation, Arp2/3-dependent actin enrichment at the cell front is markedly reduced, enabling faster and more persistent mDia1-dependent forward locomotion that facilitates chemotactic migration to lymph nodes [141]. In addition, upon bacterial sensing, the antigen micropinocytosis of DCs is decreased, and subsequently, the ionic channel TRPML1 (transient receptor potential cation channel, mucolipin subfamily, member 1) is activated for lysosomal calcium release, leading to rearrangement of the actin-based motor protein myosin II at the cell rear, which promotes fast and directional migration [142]. Therefore, cytoskeletal networks are dynamically reorganized by various intracellular pathways to ensure the proper migration of DCs, in accordance with their maturation stages and functional properties.

\section{DYSREGULATION OF DC MIGRATION IN IMMUNE DISEASES}

Consistent with the essential role of DC migration in both initiating protective immunity and maintaining immune tolerance, dysregulated trafficking of DCs results in disturbance of immune homeostasis, manifested by delayed and inefficient priming of protective T-cell immune responses on the one hand but aberrant inflammatory activation due to impaired immune tolerance on the other hand, both of which lead to the immunopathogenesis of various inflammatory and autoimmune diseases. Here, we discuss the dysregulation of DC migration in immunological disorders and the pathogenesis of autoimmune diseases and infectious diseases, focusing on rheumatoid arthritis (RA) and coronavirus disease 2019 (COVID-19).

\section{DC migration in rheumatoid arthritis}

Various chemokines/receptors are closely related to the development of autoimmune diseases, such as multiple sclerosis (MS), systemic lupus erythematosus (SLE), rheumatoid arthritis (RA), and inflammatory bowel diseases (IBDs). Increased expression levels of DC-related chemokines and their receptors are detected in blood, synovial fluid, and synovial tissue in patients with RA, and some of 
them serve as promising biomarkers of RA disease activity/severity [143]. Early-phase preclinical trials targeting the chemokine system for the treatment of RA have yielded promising results [144]. In particular, CCR7-mediated DC migration is essential for the development of collagen-induced arthritis (CIA), a mouse model of rheumatoid arthritis. Treatment with the immune modulator FTY720 significantly inhibited the incidence and severity of CIA by reducing CCL19 secretion and CCR7-based function in DCs [145]. Treatment of humanized CCR7 mice with an anti-human CCR7 $\mathrm{mAb}$ prevented the induction of $\mathrm{CIA}$ and inhibited $\mathrm{CIA}$ progression, suggesting a potential strategy for the clinical treatment of RA [146]. In addition, blocking matrix metalloproteinase-9 (MMP9) with a specific antibody significantly suppressed the development of CIA in mice by inhibiting CCR7-triggered DC trafficking [147]. These studies highlight CCR7 as a potential therapeutic target for autoimmune diseases such as RA.

\section{DC migration in COVID-19}

The COVID-19 pandemic caused by SARS-CoV-2 has led to $>3$ million deaths worldwide. Infection with SARS-CoV-2 induces the release of large amounts of DAMPs (damage-associated molecular patterns) and PAMPs (pathogen-associated molecular patterns), which leads to profound production of inflammatory mediators, including IL- 6 and IL-1 $\beta$, plus chemokines, such as MCP-1 and MIP$1 a$, derived from monocytes and macrophages [148]. These inflammatory and chemotactic cytokines cooperatively recruit innate and adaptive cells from blood into the site of infection, resulting in amplified lung inflammation [149].

Despite strongly activated innate immunity and inflammatory responses, acute SARS-CoV-2 infection impairs DC function and antigen-specific T-cell responses [150] and dampens antiviral type I and type III interferon responses [151]. pDCs, CDC1s, and CDC2s all display decreased expression of CD80, CD86, CCR7 and HLA-DR after stimulation with TLR ligands in acute patients compared to healthy controls, indicating potentially reduced maturation and migration of DC subsets following acute SARS-CoV-2 infection [150]. The bronchoalveolar lavage fluid (BALF) of patients with severe/critical COVID-19 infection contains higher proportions of macrophages and neutrophils but lower proportions of $\mathrm{mDCs}$, pDCs and T cells than the BALF of those with moderate infection [152]. Overall, impaired migration or antigen-presenting function of DCs likely results in a blunted T-cell response to eliminate invading SARS-CoV-2. It will be important to investigate the mechanisms by which SARS-CoV-2 infection impairs DC function to escape immune attack.

\section{CONCLUSIONS AND PERSPECTIVES}

Despite our increasing understanding of the immunological roles and molecular mechanisms of DC migration during inflammation and immunity, several intriguing and important aspects of this field remain elusive and are worthy of further investigation.

DCs serve distinct immunological functions, including antigen sensing, antigen capture, inflammatory cytokine production, chemotactic migration, and T-cell priming and regulation. The overlap between the migratory processes of DCs and other aspects of DC function is critical to ensuring the most efficient and beneficial immunological outcome, but the underlying mechanisms are poorly understood. Furthermore, DC migration is influenced by multiple extracellular signals derived from the immune microenvironment, such as extracellular matrix and epithelial cells, as well as a complicated intracellular molecular network involving metabolic and epigenetic pathways. However, how DCs coordinate these signals to achieve proper and effective polarization and migration remains elusive. In addition, an increasing number of reports have shown that bidirectional interactions between DCs and neuronal cells play important roles in mediating neuroinflammatory responses in the context of infection and injury. However, how neuropeptides and neurotransmitters participate in the regulation of DC migration and, conversely, how the chemokine system in DCs modulates the pathogenesis of neurodegenerative diseases are worthy of further investigation. In summary, with the rapid development of single-cell technologies, single-molecule technologies, highresolution in vivo imaging technologies and multiomics-based technologies, it will be possible to better elucidate the molecular events and pathways that regulate DC migration under various inflammatory and immunological processes and reveal novel therapeutic strategies targeting DC migration for related immune diseases.

\section{REFERENCES}

1. Worbs T, Hammerschmidt SI, Forster R. Dendritic cell migration in health and disease. Nat Rev Immunol. 2017;17:30-48.

2. Qian C, Cao X. Dendritic cells in the regulation of immunity and inflammation. Semin Immunol. 2018;35:3-11.

3. Iwasaki A, Medzhitov R. Control of adaptive immunity by the innate immune system. Nat. Immunol. 2015;16:343-53.

4. Steinman RM. Decisions about dendritic cells: past, present, and future. Annu Rev. Immunol. 2012;30:1-22.

5. Randolph GJ, Ochando J, Partida-Sanchez S. Migration of dendritic cell subsets and their precursors. Annu Rev Immunol. 2008;26:293-316.

6. Kashem SW, Haniffa M, Kaplan DH. Antigen-Presenting Cells in the Skin. Annu Rev Immunol. 2017;35:469-99.

7. Takeuchi O, Akira S. Pattern recognition receptors and inflammation. Cell. 2010;140:805-20.

8. Förster R, Schubel A, Breitfeld D, Kremmer E, Renner-Müller I, Wolf E, et al. CCR7 coordinates the primary immune response by establishing functional microenvironments in secondary lymphoid organs. Cell. 1999;99:23-33.

9. Jang MH, Sougawa N, Tanaka T, Hirata T, Hiroi T, Tohya K, et al. CCR7 is critically important for migration of dendritic cells in intestinal lamina propria to mesenteric lymph nodes. J. Immunol. 2006;176:803-10.

10. Gunn MD, Kyuwa S, Tam C, Kakiuchi T, Matsuzawa A, Williams LT, et al. Mice lacking expression of secondary lymphoid organ chemokine have defects in lymphocyte homing and dendritic cell localization. J Exp Med. 1999;189:451-60.

11. Ulvmar MH, Werth K, Braun A, Kelay P, Hub E, Eller K, et al. The atypical chemokine receptor CCRL1 shapes functional CCL21 gradients in lymph nodes. Nat Immunol. 2014;15:623-30.

12. Braun A, Worbs T, Moschovakis GL, Halle S, Hoffmann K, Bölter J, et al. Afferent lymph-derived $T$ cells and DCs use different chemokine receptor CCR7dependent routes for entry into the lymph node and intranodal migration. Nat Immunol. 2011;12:879-87.

13. Ohl L, Mohaupt M, Czeloth N, Hintzen G, Kiafard Z, Zwirner J, et al. CCR7 governs skin dendritic cell migration under inflammatory and steady-state conditions. Immunity. 2004;21:279-88.

14. Hintzen G, Ohl L, del Rio ML, Rodriguez-Barbosa Jl, Pabst O, Kocks JR, et al. Induction of tolerance to innocuous inhaled antigen relies on a CCR7dependent dendritic cell-mediated antigen transport to the bronchial lymph node. J Immunol. 2006;177:7346-54.

15. Worbs T, Bode U, Yan S, Hoffmann MW, Hintzen G, Bernhardt G, et al. Oral tolerance originates in the intestinal immune system and relies on antigen carriage by dendritic cells. J Exp Med. 2006;203:519-27.

16. Davalos-Misslitz AC, Rieckenberg J, Willenzon S, Worbs T, Kremmer E, Bernhardt $\mathrm{G}$, et al. Generalized multi-organ autoimmunity in CCR7-deficient mice. Eur J Immunol. 2007;37:613-22.

17. Kurobe H, Liu C, Ueno T, Saito F, Ohigashi I, Seach N, et al. CCR7-dependent cortex-to-medulla migration of positively selected thymocytes is essential for establishing central tolerance. Immunity. 2006;24:165-77.

18. Cao X, Zhang W, Wan T, He L, Chen T, Yuan Z, et al. Molecular cloning and characterization of a novel CXC chemokine macrophage inflammatory protein-2 gamma chemoattractant for human neutrophils and dendritic cells. J Immunol. 2000;165:2588-95.

19. Shellenberger TD, Wang M, Gujrati M, Jayakumar A, Strieter RM, Burdick MD, et al. BRAK/CXCL14 is a potent inhibitor of angiogenesis and a chemotactic factor for immature dendritic cells. Cancer Res. 2004;64:8262-70.

20. Schaerli P, Willimann K, Ebert LM, Walz A, Moser B. Cutaneous CXCL14 targets blood precursors to epidermal niches for Langerhans cell differentiation. Immunity. 2005;23:331-42.

21. Lee J, Zhang J, Chung YJ, Kim JH, Kook CM, González-Navajas JM, et al. Inhibition of IRF4 in dendritic cells by PRR-independent and -dependent signals inhibit Th2 and promote Th17 responses. Elife 2020;9:e49416 (1-30). 
22. Ho AW, Prabhu N, Betts RJ, Ge MQ, Dai X, Hutchinson PE, et al. Lung CD103+ dendritic cells efficiently transport influenza virus to the lymph node and load viral antigen onto MHC class I for presentation to CD8 T cells. J Immunol. 2011;187:6011-21.

23. Helft J, Manicassamy B, Guermonprez P, Hashimoto D, Silvin A, Agudo J, et al. Cross-presenting $\mathrm{CD} 103+$ dendritic cells are protected from influenza virus infection. J Clin Invest. 2012;122:4037-47.

24. Shekhar S, Peng Y, Wang S, Yang X. CD103+ lung dendritic cells (LDCs) induce stronger Th1/Th17 immunity to a bacterial lung infection than CD11b(hi) LDCs. Cell Mol Immunol. 2018;15:377-87.

25. Ding Y, Guo Z, Liu Y, Li X, Zhang Q, Xu X, et al. The lectin Siglec-G inhibits dendritic cell cross-presentation by impairing MHC class I-peptide complex formation. Nat Immunol. 2016;17:1167-75.

26. Ng SL, Teo YJ, Setiagani YA, Karjalainen K, Ruedl C. Type 1 conventional CD103 $(+)$ dendritic cells control effector CD8(+) T cell migration, survival, and memory responses during influenza infection. Front Immunol. 2018;9:3043.

27. Henri S, Poulin LF, Tamoutounour S, Ardouin L, Guilliams M, de Bovis B, et al. CD207+ CD103+ dermal dendritic cells cross-present keratinocyte-derived antigens irrespective of the presence of Langerhans cells. J Exp Med. 2010;207:189-206

28. Bedoui S, Whitney PG, Waithman J, Eidsmo L, Wakim L, Caminschi I, et al. Crosspresentation of viral and self antigens by skin-derived CD103+ dendritic cells. Nat Immunol. 2009;10:488-95.

29. Stary G, Olive A, Radovic-Moreno AF, Gondek D, Alvarez D, Basto PA, et al. VACCINES. A mucosal vaccine against Chlamydia trachomatis generates two waves of protective memory T cells. Science. 2015;348:aaa8205.

30. Sokol CL, Camire RB, Jones MC, Luster AD. The chemokine receptor CCR8 promotes the migration of dendritic cells into the lymph node parenchyma to initiate the allergic immune response. Immunity. 2018;49:449-63.

31. Moon HG, Kim SJ, Jeong JJ, Han SS, Jarjour NN, Lee H, et al. Airway epithelial cell-derived colony stimulating factor-1 promotes allergen sensitization. Immunity. 2018;49:275-87.e275.

32. Moon HG, Kim SJ, Lee MK, Kang H, Choi HS, Harijith A, et al. Colony-stimulating factor 1 and its receptor are new potential therapeutic targets for allergic asthma. Allergy. 2020;75:357-69.

33. Perner C, Flayer CH, Zhu X, Aderhold PA, Dewan Z, Voisin T, et al. Substance P release by sensory neurons triggers dendritic cell migration and initiates the type-2 immune response to allergens. Immunity. 2020;53:1063-77.

34. Leon B, Lopez-Bravo M, Ardavin C. Monocyte-derived dendritic cells formed at the infection site control the induction of protective $\mathrm{T}$ helper 1 responses against Leishmania. Immunity. 2007;26:519-31.

35. Tamoutounour S, Guilliams M, Montanana Sanchis F, Liu H, Terhorst D, Malosse $C$, et al. Origins and functional specialization of macrophages and of conventional and monocyte-derived dendritic cells in mouse skin. Immunity. 2013;39:925-38

36. Plantinga $M$, Guilliams $M$, Vanheerswynghels $M$, Deswarte $K$, Branco-Madeira $F$, Toussaint $\mathrm{W}$, et al. Conventional and monocyte-derived $\mathrm{CD} 11 \mathrm{~b}(+)$ dendritic cells initiate and maintain Thelper 2 cell-mediated immunity to house dust mite allergen. Immunity. 2013;38:322-35.

37. Zigmond E, Varol C, Farache J, Elmaliah E, Satpathy AT, Friedlander G, et al. Ly6C hi monocytes in the inflamed colon give rise to proinflammatory effector cells and migratory antigen-presenting cells. Immunity. 2012;37:1076-90.

38. Nakano H, Lin KL, Yanagita M, Charbonneau C, Cook DN, Kakiuchi T, et al. Bloodderived inflammatory dendritic cells in lymph nodes stimulate acute $\mathrm{T}$ helper type 1 immune responses. Nat Immunol. 2009;10:394-402.

39. Lian J, Ozga AJ, Sokol CL, Luster AD. Targeting lymph node niches enhances type 1 immune responses to immunization. Cell Rep. 2020;31:107679.

40. Cheong C, Matos I, Choi JH, Dandamudi DB, Shrestha E, Longhi MP, et al. Microbial stimulation fully differentiates monocytes to DC-SIGN/CD209(+) dendritic cells for immune T cell areas. Cell. 2010;143:416-29.

41. Bosteels C, Neyt K, Vanheerswynghels M, van Helden MJ, Sichien D, Debeuf N, et al. Inflammatory type $2 \mathrm{CDCs}$ acquire features of $\mathrm{CDC} 1 \mathrm{~s}$ and macrophages to orchestrate immunity to respiratory virus infection. Immunity. 2020;52:1039-56.

42. Seth S, Oberdörfer L, Hyde R, Hoff K, Thies V, Worbs T, et al. CCR7 essentially contributes to the homing of plasmacytoid dendritic cells to lymph nodes under steady-state as well as inflammatory conditions. J Immunol. 2011;186:3364-72.

43. Vermi W, Riboldi E, Wittamer V, Gentili F, Luini W, Marrelli S, et al. Role of ChemR23 in directing the migration of myeloid and plasmacytoid dendritic cells to lymphoid organs and inflamed skin. J Exp Med. 2005;201:509-15.

44. Vanbervliet B, Bendriss-Vermare N, Massacrier C, Homey B, de Bouteiller $O$ Brière $F$, et al. The inducible $C X C R 3$ ligands control plasmacytoid dendritic cell responsiveness to the constitutive chemokine stromal cell-derived factor 1 (SDF1)/CXCL12. J Exp Med. 2003;198:823-30.

45. Krug A, Uppaluri R, Facchetti F, Dorner BG, Sheehan KC, Schreiber RD, et al. IFNproducing cells respond to CXCR3 ligands in the presence of CXCL12 and secrete inflammatory chemokines upon activation. J Immunol. 2002;169:6079-83.

46. Diacovo TG, Blasius AL, Mak TW, Cella M, Colonna M. Adhesive mechanisms governing interferon-producing cell recruitment into lymph nodes. J Exp Med. 2005;202:687-96.

47. Umemoto E, Otani K, Ikeno T, Verjan Garcia N, Hayasaka H, Bai Z, et al. Constitutive plasmacytoid dendritic cell migration to the splenic white pulp is cooperatively regulated by CCR7- and CXCR4-mediated signaling. J Immunol. 2012;189:191-9.

48. Sisirak V, Vey N, Vanbervliet B, Duhen T, Puisieux I, Homey B, et al. CCR6/CCR10mediated plasmacytoid dendritic cell recruitment to inflamed epithelia after instruction in lymphoid tissues. Blood. 2011;118:5130-40.

49. Pascale F, Contreras V, Bonneau M, Courbet A, Chilmonczyk S, Bevilacqua C, et al. Plasmacytoid dendritic cells migrate in afferent skin lymph. J Immunol. 2008:180:5963-72

50. Yrlid U, Milling SW, Miller JL, Cartland S, Jenkins CD, MacPherson GG. Regulation of intestinal dendritic cell migration and activation by plasmacytoid dendritic cells, TNF-alpha and type 1 IFNs after feeding a TLR7/8 ligand. J Immunol. 2006;176:5205-12.

51. Wendland M, Czeloth N, Mach N, Malissen B, Kremmer E, Pabst O, et al. CCR9 is a homing receptor for plasmacytoid dendritic cells to the small intestine. Proc Natl Acad Sci USA. 2007;104:6347-52.

52. Clahsen T, Pabst O, Tenbrock K, Schippers A, Wagner N. Localization of dendritic cells in the gut epithelium requires MAdCAM-1. Clin Immunol. 2015;156:74-84.

53. Swiecki M, Miller HL, Sesti-Costa R, Cella M, Gilfillan S, Colonna M. Microbiota induces tonic CCL2 systemic levels that control pDC trafficking in steady state. Mucosal Immunol. 2017;10:936-45.

54. Heath WR, Carbone FR. The skin-resident and migratory immune system in steady state and memory: innate lymphocytes, dendritic cells and T cells. Nat Immunol. 2013;14:978-85.

55. Gallego, $C$ et al. CXCR4 signaling controls dendritic cell location and activation at steady-state and in inflammation. Blood 2021;137:2770-84.

56. Cao X. Self-regulation and cross-regulation of pattern-recognition receptor signalling in health and disease. Nat Rev Immunol. 2016;16:35-50.

57. Forster R, Davalos-Misslitz AC, Rot A. CCR7 and its ligands: balancing immunity and tolerance. Nat Rev Immunol. 2008;8:362-71.

58. Girard JP, Moussion C, Forster R. HEVs, lymphatics and homeostatic immune cell trafficking in lymph nodes. Nat Rev Immunol. 2012;12:762-73.

59. Byers MA, Calloway PA, Shannon L, Cunningham HD, Smith S, Li F, et al. Arrestin 3 mediates endocytosis of CCR7 following ligation of CCL19 but not CCL21. J Immunol. 2008;181:4723-32.

60. Haessler U, Pisano M, Wu M, Swartz MA. Dendritic cell chemotaxis in 3D under defined chemokine gradients reveals differential response to ligands CCL21 and CCL19. Proc Natl Acad Sci USA. 2011;108:5614-9.

61. Weber M, Hauschild R, Schwarz J, Moussion C, de Vries I, Legler DF, et al. Interstitial dendritic cell guidance by haptotactic chemokine gradients. Science. 2013;339:328-32.

62. Sánchez-Sánchez N, Riol-Blanco L, de la Rosa G, Puig-Kröger A, García-Bordas J, Martín $D$, et al. Chemokine receptor CCR7 induces intracellular signaling that inhibits apoptosis of mature dendritic cells. Blood. 2004;104:619-25.

63. Riol-Blanco L, Sánchez-Sánchez N, Torres A, Tejedor A, Narumiya S, Corbí AL, et al. The chemokine receptor CCR7 activates in dendritic cells two signaling modules that independently regulate chemotaxis and migratory speed. J Immunol. 2005;174:4070-80.

64. Liu S, Wu J, Zhang T, Qian B, Wu P, Li L, et al. Complement C1q chemoattracts human dendritic cells and enhances migration of mature dendritic cells to CCL19 via activation of AKT and MAPK pathways. Mol Immunol. 2008;46:242-9.

65. Guo Z, Zhang M, Tang H, Cao X. Fas signal links innate and adaptive immunity by promoting dendritic-cell secretion of CC and CXC chemokines. Blood. 2005;106:2033-41.

66. Fruman DA, Bismuth G. Fine tuning the immune response with PI3K. Immunol Rev. 2009;228:253-72.

67. Del Prete A, Vermi W, Dander E, Otero K, Barberis L, Luini W, et al. Defective dendritic cell migration and activation of adaptive immunity in PI3Kgammadeficient mice. EMBO J. 2004:23:3505-15.

68. Matheu MP, Deane JA, Parker I, Fruman DA, Cahalan MD. Class IA phosphoinositide 3-kinase modulates basal lymphocyte motility in the lymph node. J Immunol. 2007;179:2261-9.

69. Chin YR, Toker A. The actin-bundling protein palladin is an Akt1-specific substrate that regulates breast cancer cell migration. Mol Cell. 2010;38:333-44.

70. Krycer JR, Sharpe L, Luu W, Brown AJ. The Akt-SREBP nexus: cell signaling meets lipid metabolism. Trends Endocrinol Metab. 2010;21:268-76.

71. Baus D, Heermeier K, De Hoop M, Metz-Weidmann C, Gassenhuber J, Dittrich W, et al. Identification of a novel AS160 splice variant that regulates GLUT4 
translocation and glucose-uptake in rat muscle cells. Cell Signal. 2008;20:2237-46.

72. Liu J, Cao X. Regulatory dendritic cells in autoimmunity: A comprehensive review. J Autoimmun. 2015;63:1-12.

73. Liu J, Han C, Xie B, Wu Y, Liu S, Chen K, et al. Rhbdd3 controls autoimmunity by suppressing the production of IL-6 by dendritic cells via K27-linked ubiquitination of the regulator NEMO. Nat Immunol. 2014;15:612-22.

74. Zidar DA, Violin JD, Whalen EJ, Lefkowitz RJ. Selective engagement of $G$ protein coupled receptor kinases (GRKs) encodes distinct functions of biased ligands. Proc Natl Acad Sci USA. 2009;106:9649-54.

75. Kohout TA, Nicholas SL, Perry SJ, Reinhart G, Junger S, Struthers RS. Differential desensitization, receptor phosphorylation, beta-arrestin recruitment, and ERK1/ 2 activation by the two endogenous ligands for the CC chemokine receptor 7 . J Biol Chem. 2004;279:23214-22.

76. Marsland BJ, Bättig P, Bauer M, Ruedl C, Lässing U, Beerli RR, et al. CCL19 and CCL21 induce a potent proinflammatory differentiation program in licensed dendritic cells. Immunity. 2005;22:493-505.

77. Yanagawa $Y$, Onoe K. CCR7 ligands induce rapid endocytosis in mature dendritic cells with concomitant up-regulation of Cdc42 and Rac activities. Blood. 2003;101:4923-9.

78. Baratin M, Foray C, Demaria O, Habbeddine M, Pollet E, Maurizio J, et al. Homeostatic NF-kappaB signaling in steady-state migratory dendritic cells regulates immune homeostasis and tolerance. Immunity. 2015;42:627-39.

79. Rescigno M, Martino M, Sutherland CL, Gold MR, Ricciardi-Castagnoli P. Dendritic cell survival and maturation are regulated by different signaling pathways. J Exp Med. 1998;188:2175-80.

80. Krappmann D, Wegener E, Sunami Y, Esen M, Thiel A, Mordmuller B, et al. The IkappaB kinase complex and NF-kappaB act as master regulators of lipopolysaccharide-induced gene expression and control subordinate activation of AP-1. Mol Cell Biol. 2004;24:6488-500.

81. Yamakita Y, Matsumura F, Lipscomb MW, Chou PC, Werlen G, Burkhardt JK, et al. Fascin1 promotes cell migration of mature dendritic cells. J Immunol. 2011;186:2850-9.

82. Hagerbrand K, Westlund J, Yrlid U, Agace W, Johansson-Lindbom B. MyD88 signaling regulates steady-state migration of intestinal CD103+ dendritic cells independently of TNF-alpha and the gut microbiota. J Immunol. 2015;195:2888-99.

83. Wang L, Liu Q, Sun $Q$, Zhang C, Chen T, Cao X. TLR4 signaling in cancer cells promotes chemoattraction of immature dendritic cells via autocrine CCL2O. Biochem Biophys Res Commun. 2008;366:852-6.

84. Chen T, Guo J, Yang M, Han C, Zhang M, Chen W, et al. Cyclosporin A impairs dendritic cell migration by regulating chemokine receptor expression and inhibiting cyclooxygenase-2 expression. Blood. 2004;103:413-21.

85. Liu Q, Chen T, Chen G, Shu X, Sun A, Ma P, et al. Triptolide impairs dendritic cell migration by inhibiting CCR7 and COX-2 expression through PI3-K/Akt and NFkappaB pathways. Mol Immunol. 2007;44:2686-96.

86. Liu Q, Chen T, Chen G, Li N, Wang J, Ma P, et al. Immunosuppressant triptolide inhibits dendritic cell-mediated chemoattraction of neutrophils and T cells through inhibiting Stat3 phosphorylation and NF-kappaB activation. Biochem Biophys Res Commun. 2006;345:1122-30.

87. Dang EV, Barbi J, Yang HY, Jinasena D, Yu H, Zheng Y, et al. Control of $T(H) 17 / T$ (reg) balance by hypoxia-inducible factor 1. Cell. 2011;146:772-84.

88. Doedens AL, Phan AT, Stradner MH, Fujimoto JK, Nguyen JV, Yang E, et al. Hypoxia-inducible factors enhance the effector responses of $\mathrm{CD} 8(+) \mathrm{T}$ cells to persistent antigen. Nat Immunol. 2013;14:1173-82.

89. Colgan SP, Furuta GT, Taylor CT. Hypoxia and Innate Immunity: keeping Up with the HIFsters. Annu Rev Immunol. 2020;38:341-63.

90. McGettrick AF, O'Neill LAJ. The role of HIF in Immunity and Inflammation. Cell Metab. 2020;32:524-36.

91. Nizet $\mathrm{V}$, Johnson RS. Interdependence of hypoxic and innate immune responses. Nat Rev Immunol. 2009;9:609-17.

92. Kohler T, Reizis B, Johnson RS, Weighardt H, Forster I. Influence of hypoxiainducible factor 1alpha on dendritic cell differentiation and migration. Eur $\mathrm{J}$ Immunol. 2012;42:1226-36.

93. Ricciardi A, Elia AR, Cappello P, Puppo M, Vanni C, Fardin P, et al. Transcriptome of hypoxic immature dendritic cells: modulation of chemokine/receptor expression. Mol Cancer Res. 2008;6:175-85.

94. Cramer T, Yamanishi Y, Clausen BE, Förster I, Pawlinski R, Mackman N, et al. HIF1alpha is essential for myeloid cell-mediated inflammation. Cell. 2003;112:645-57.

95. Liu J, Zhang X, Chen K, Cheng Y, Liu S, Xia M, et al. CCR7 chemokine receptorinducible Inc-Dpf3 restrains dendritic cell migration by inhibiting HIF-1alphamediated glycolysis. Immunity. 2019;50:600-15.

96. Suzuki S, Honma K, Matsuyama T, Suzuki K, Toriyama K, Akitoyo I, et al. Critical roles of interferon regulatory factor 4 in CD11bhighCD8alpha- dendritic cell development. Proc Natl Acad. Sci USA. 2004:101:8981-6.
97. Tamura T, Tailor P, Yamaoka K, Kong HJ, Tsujimura H, O'Shea JJ, et al. IFN regulatory factor- 4 and -8 govern dendritic cell subset development and their functional diversity. J Immunol. 2005;174:2573-81.

98. Edelson BT, KC W, Juang R, Kohyama M, Benoit LA, Klekotka PA, et al. Peripheral CD103+ dendritic cells form a unified subset developmentally related to CD8alpha+ conventional dendritic cells. J Exp Med. 2010;207:823-36.

99. Bajana S, Roach K, Turner S, Paul J, Kovats S. IRF4 promotes cutaneous dendritic cell migration to lymph nodes during homeostasis and inflammation. J Immunol. 2012;189:3368-77.

100. Persson EK, Uronen-Hansson H, Semmrich M, Rivollier A, Hägerbrand K, Marsal J, et al. IRF4 transcription-factor-dependent $\mathrm{CD} 103(+) \mathrm{CD} 11 \mathrm{~b}(+)$ dendritic cells drive mucosal T helper 17 cell differentiation. Immunity. 2013;38:958-69.

101. Schlitzer A, McGovern N, Teo P, Zelante T, Atarashi K, Low D, et al. IRF4 transcription factor-dependent CD11b + dendritic cells in human and mouse control mucosal IL-17 cytokine responses. Immunity. 2013;38:970-83.

102. Akbari M, Honma K, Kimura D, Miyakoda M, Kimura K, Matsuyama T, et al. IRF4 in dendritic cells inhibits IL-12 production and controls Th1 immune responses against Leishmania major. J Immunol. 2014;192:2271-9.

103. Vander Lugt B, Khan AA, Hackney JA, Agrawal S, Lesch J, Zhou M, et al. Transcriptional programming of dendritic cells for enhanced MHC class II antigen presentation. Nat Immunol. 2014;15:161-7.

104. Xiao K, Sun J, Kim J, Rajagopal S, Zhai B, Villén J, et al. Global phosphorylation analysis of beta-arrestin-mediated signaling downstream of a seven transmembrane receptor (7TMR). Proc Natl Acad Sci USA. 2010;107:15299-304.

105. Eichel $K$, Jullie $D$, von Zastrow M. beta-Arrestin drives MAP kinase signalling from clathrin-coated structures after GPCR dissociation. Nat Cell Biol. 2016;18:303-10.

106. Hauser MA, Schaeuble K, Kindinger I, Impellizzieri $D$, Krueger WA, Hauck $C R$, et al. Inflammation-induced CCR7 oligomers form scaffolds to integrate distinct signaling pathways for efficient cell migration. Immunity. 2016;44:59-72.

107. Otero C, Groettrup M, Legler DF. Opposite fate of endocytosed CCR7 and its ligands: recycling versus degradation. J Immunol. 2006;177:2314-23.

108. Schaeuble K, Hauser MA, Rippl AV, Bruderer R, Otero C, Groettrup M, et al. Ubiquitylation of the chemokine receptor CCR7 enables efficient receptor recycling and cell migration. J Cell Sci. 2012;125:4463-74.

109. Laufer JM, Hauser MA, Kindinger I, Purvanov V, Pauli A, Legler DF. Chemokine receptor CCR7 triggers an endomembrane signaling complex for spatial Rac activation. Cell Rep. 2019;29:995-1009.

110. Kiermaier E, Moussion C, Veldkamp CT, Gerardy-Schahn R, de Vries I, Williams $\mathrm{LG}$, et al. Polysialylation controls dendritic cell trafficking by regulating chemokine recognition. Science. 2016;351:186-90.

111. Liu J, Qian C, Cao X. Post-translational modification control of innate immunity. Immunity. 2016;45:15-30.

112. Alvarez-Errico D, Vento-Tormo R, Sieweke M, Ballestar E. Epigenetic control of myeloid cell differentiation, identity and function. Nat Rev Immunol. 2015;15:7-17.

113. Zhang Q, Cao X. Epigenetic Remodeling in Innate Immunity and Inflammation. Annu Rev Immunol. 2021;39:279-311.

114. Moran TP, Nakano $H$, Kondilis-Mangum HD, Wade PA, Cook DN. Epigenetic control of Ccr7 expression in distinct lineages of lung dendritic cells. J Immunol. 2014:193:4904-13.

115. Schliehe C, Flynn EK, Vilagos B, Richson U, Swaminanthan S, Bosnjak B, et al. The methyltransferase Setdb2 mediates virus-induced susceptibility to bacterial superinfection. Nat Immunol. 2015;16:67-74.

116. Ferrara G, Benzi A, Sturla L, Marubbi $D$, Frumento $D$, Spinelli $S$, et al. Sirt6 inhibition delays the onset of experimental autoimmune encephalomyelitis by reducing dendritic cell migration. J Neuroinflammation. 2020;17:228.

117. Fang $\mathrm{H}$, Wu Y, Huang X, Wang W, Ang B, Cao X, et al. Toll-like receptor 4 (TLR4) is essential for Hsp70-like protein 1 (HSP70L1) to activate dendritic cells and induce Th1 response. J Biol Chem. 2011;286:30393-400.

118. Liu S, Yi L, Ling M, Jiang J, Song L, Liu J, et al. HSP70L1-mediated intracellular priming of dendritic cell vaccination induces more potent CTL response against cancer. Cell Mol. Immunol. 2018;15:135-45.

119. Yi L, Li Z, Hu T, Liu J, Li N, Cao X, et al. Intracellular HSP70L1 inhibits human dendritic cell maturation by promoting suppressive H3K27me3 and H2AK119Ub1 histone modifications. Cell Mol Immunol. 2020;17:85-94.

120. Turner M, Galloway A, Vigorito E. Noncoding RNA and its associated proteins as regulatory elements of the immune system. Nat Immunol. 2014;15:484-91.

121. Wang $P, X u e ~ Y, \operatorname{Han} Y$, Lin $L, W u C, X u S$, et al. The STAT3-binding long noncoding RNA Inc-DC controls human dendritic cell differentiation. Science. 2014:344:310-3.

122. Xing Z, Lin A, Li C, Liang K, Wang S, Liu Y, et al. IncRNA directs cooperative epigenetic regulation downstream of chemokine signals. Cell. 2014;159:1110-25.

123. Wang $H$, Hu X, Huang $M$, Liu J, Gu Y, Ma L, et al. Mett|3-mediated mRNA m(6)A methylation promotes dendritic cell activation. Nat Commun. 2019;10:1898. 
124. Kaelin WG Jr., McKnight SL. Influence of metabolism on epigenetics and disease. Cell. 2013;153:56-69.

125. Pearce EJ, Everts B. Dendritic cell metabolism. Nat Rev Immunol. 2015;15:18-29.

126. Westerterp M, Gautier EL, Ganda A, Molusky MM, Wang W, Fotakis P, et al. Cholesterol accumulation in dendritic cells links the inflammasome to acquired immunity. Cell Metab. 2017;25:1294-304.

127. Tiniakou I, Drakos E, Sinatkas V, Van Eck M, Zannis VI, Boumpas D, et al. High-density lipoprotein attenuates Th1 and th17 autoimmune responses by modulating dendritic cell maturation and function. J Immunol. 2015;194:4676-87.

128. Lühr JJ, Alex N, Amon L, Kräter M, Kubánková M, Sezgin E, et al. Maturation of monocyte-derived DCs leads to increased cellular stiffness, higher membrane fluidity, and changed lipid composition. Front Immunol. 2020;11:590121.

129. Sawada Y, Honda T, Hanakawa S, Nakamizo S, Murata T, Ueharaguchi-Tanada Y, et al. Resolvin E1 inhibits dendritic cell migration in the skin and attenuates contact hypersensitivity responses. J Exp Med. 2015;212:1921-30.

130. Krawczyk CM, Holowka T, Sun J, Blagih J, Amiel E, DeBerardinis RJ, et al. Toll-like receptor-induced changes in glycolytic metabolism regulate dendritic cell activation. Blood. 2010;115:4742-9.

131. Everts B, Amiel E, Huang SC, Smith AM, Chang CH, Lam WY, et al. TLR-driven early glycolytic reprogramming via the kinases TBK1-IKKvarepsilon supports the anabolic demands of dendritic cell activation. Nat Immunol. 2014;15:323-32.

132. Guak H, Al Habyan S, Ma EH, Aldossary H, Al-Masri M, Won SY, et al. Glycolytic metabolism is essential for CCR7 oligomerization and dendritic cell migration. Nat Commun. 2018;9:2463.

133. Moreau HD, Piel M, Voituriez R, Lennon-Dumenil AM. Integrating physical and molecular insights on immune cell migration. Trends Immunol. 2018;39:632-43.

134. Lämmermann T, Renkawitz J, Wu X, Hirsch K, Brakebusch C, Sixt M. Cdc42dependent leading edge coordination is essential for interstitial dendritic cell migration. Blood. 2009;113:5703-10.

135. Harada Y, Tanaka Y, Terasawa M, Pieczyk M, Habiro K, Katakai T, et al. DOCK8 is a Cdc42 activator critical for interstitial dendritic cell migration during immune responses. Blood. 2012;119:4451-61.

136. Krishnaswamy JK, Singh A, Gowthaman U, Wu R, Gorrepati P, Sales Nascimento $\mathrm{M}$, et al. Coincidental loss of DOCK8 function in NLRP10-deficient and $\mathrm{C} 3 \mathrm{H} / \mathrm{HeJ}$ mice results in defective dendritic cell migration. Proc Natl Acad Sci USA. 2015;112:3056-61.

137. Randall KL, Lambe $T$, Johnson AL, Treanor $B$, Kucharska $E$, Domaschenz $H$, et al. Dock8 mutations cripple $B$ cell immunological synapses, germinal centers and long-lived antibody production. Nat Immunol. 2009;10:1283-91.

138. Gunawan M, Venkatesan N, Loh JT, Wong JF, Berger $\mathrm{H}, \mathrm{Neo} W \mathrm{H}$, et al. The methyltransferase Ezh2 controls cell adhesion and migration through direct methylation of the extranuclear regulatory protein talin. Nat Immunol. 2015;16:505-16.

139. Fayngerts SA, Wang Z, Zamani A, Sun H, Boggs AE, Porturas TP, et al. Direction of leukocyte polarization and migration by the phosphoinositide-transfer protein TIPE2. Nat Immunol. 2017;18:1353-60.

140. de Winde CM, Munday C, Acton SE. Molecular mechanisms of dendritic cell migration in immunity and cancer. Med Microbiol Immunol. 2020;209:515-29.
141. Vargas $P$, Maiuri $P$, Bretou $M$, Sáez $P J$, Pierobon $P$, Maurin $M$, et al. Innate control of actin nucleation determines two distinct migration behaviours in dendritic cells. Nat Cell Biol. 2016;18:43-53.

142. Bretou M, Sáez PJ, Sanséau D, Maurin M, Lankar D, Chabaud M, et al. Lysosome signaling controls the migration of dendritic cells. Sci Immunol. 2017;2:eaak9573 (1-11).

143. Coutant $F$, Miossec P. Altered dendritic cell functions in autoimmune diseases: distinct and overlapping profiles. Nat Rev Rheumatol. 2016;12:703-15.

144. Miyabe Y, Lian J, Miyabe C, Luster AD. Chemokines in rheumatic diseases: pathogenic role and therapeutic implications. Nat Rev Rheumatol. 2019;15:731-46.

145. Han Y, Li X, Zhou Q, Jie H, Lao X, Han J, et al. FTY720 Abrogates collageninduced arthritis by hindering dendritic cell migration to local lymph nodes. J Immunol. 2015;195:4126-35.

146. Moschovakis GL, Bubke A, Friedrichsen M, Ristenpart J, Back JW, Falk CS, et al. The chemokine receptor CCR7 is a promising target for rheumatoid arthritis therapy. Cell Mol Immunol. 2019;16:791-9.

147. He J, Li X, Zhuang J, Han J, Luo G, Yang F, et al. Blocking matrix metalloproteinase- 9 abrogates collagen-induced arthritis via inhibiting dendritic cell migration. J Immunol. 2018;201:3514-23.

148. Cao X. COVID-19: immunopathology and its implications for therapy. Nat Rev Immunol. 2020;20:269-70.

149. Merad M, Martin JC. Pathological inflammation in patients with COVID-19: a key role for monocytes and macrophages. Nat Rev Immunol. 2020;20:355-62.

150. Zhou R, To KK, Wong YC, Liu L, Zhou B, Li X, et al. Acute SARS-CoV-2 infection impairs dendritic cell and T cell responses. Immunity. 2020;53:864-77.

151. Blanco-Melo D, Nilsson-Payant BE, Liu WC, Uhl S, Hoagland D, Møller R, et al. Imbalanced host response to SARS-CoV-2 drives development of COVID-19. Cell. 2020;181:1036-45.e1039.

152. Liao M, Liu Y, Yuan J, Wen Y, Xu G, Zhao J, et al. Single-cell landscape of bronchoalveolar immune cells in patients with COVID-19. Nat Med. 2020;26:842-4.

\section{ACKNOWLEDGEMENTS}

This work was supported by grants from the National Natural Science Foundation of China (32070903, 31870909, and 81788101).

\section{Declarations (Ethics)}

\section{COMPETING INTERESTS}

The authors declare no competing interests.

\section{ADDITIONAL INFORMATION}

Correspondence and requests for materials should be addressed to J.L. or X.C.

Reprints and permission information is available at http://www.nature.com/ reprints 